Ensino, Saúde e Ambiente -V4 (2), pp. 58-70, ago. 2011

\title{
SABERES E FAZERES DO EDUCADOR QUÍMICO, SUAS MÚLTIPLAS RELAÇÕES E DIMENSÕES - A EXPERIÊNCIA DO PROGRAMA DE PÓS- GRADUAÇÃO EM ENSINO DE CIÊNCIAS DA UNIVERSIDADE DE BRASÍLIA - PPGEC/UnB \\ THE KNOWLEDGES AND PRACTICES OF CHEMISTRY EDUCATORS, THEIR MULTIPLE RELATIONS AND DIMENSIONS - THE EXPERIENCE OF THE PROFESSIONAL GRADUATE PROGRAM IN SCIENCE EDUCATION IN THE UNIVERSITY OF BRASÍLIA
}

\author{
Ricardo Gauche, gauche@unb.br \\ Roberto Ribeiro da Silva (PPGEC-IQ/UnB), bobsilva@unb.br \\ Patrícia Fernandes Lootens Machado (IQ/UnB), plootens@unb.br \\ Joice de Aguiar Baptista (IQ/UnB), joice@unb.br \\ Gerson de Souza Mól (PPGEC-IQ/UnB), gmol@unb.br \\ Wildson Luiz Pereira dos Santos (PPGEC-IQ/UnB), wildson@unb.br \\ Instituto de Química - Universidade de Brasília \\ Campus Darcy Ribeiro - Asa Norte \\ Caixa Postal 04478 \\ Brasília-DF, 70904-970
}

\begin{abstract}
Resumo
O presente trabalho apresenta uma experiência da Universidade de Brasília, em curso, no que tange às suas contribuições para o avanço do ensino e da formação em Química, em âmbito nacional. Para tanto, contém a síntese da história, da natureza, dos impactos no contexto escolar e das linhas de pesquisa do Programa de Pós-Graduação em Ensino de Ciências da Universidade de Brasília (PPGEC/UnB), em especial do Mestrado Profissional em Ensino de Ciências, no tocante à Pesquisa em Ensino de Química. Trata-se de contribuição na perspectiva de ampliar a explicitação, socialização e análise de suas características, dos pressupostos teóricos que o fundamentam, bem como de resultados na prática do ensino escolar.
\end{abstract}

Palavras-chave: Ensino de Química, Programa de Pós-graduação em Ensino de Ciências, Pesquisa em Ensino de Química.

\begin{abstract}
The present paper presents the experience in course in the University of Brasilia regarding the contribution for the advancement of education and training in Chemistry. It contains a summary of the history, nature, school context, impacts on the school system and research lines (especially the ones related to Chemistry teaching) of the Professional Graduate Program in Science Education. It also explicits the analysis of its characteristics, theoretical assumptions and results in the practical teaching in schools.
\end{abstract}

Keywords: Chemistry teaching, Professional Graduate Program in Science Education, Research in Chemical Education.

Historicamente, o Instituto de Química da Universidade de Brasília (IQ/UnB) tem-se preocupado de maneira especial com a Educação para a Ciência, especificamente 
com o Ensino de Química. Nesse sentido, diversas ações são desenvolvidas, há anos, resultando em: projetos de pesquisas, projetos de extensão, produção de artigos e livros, apresentação de palestras, cursos e comunicações em congressos, realização de cursos de formação continuada a professores de ensino fundamental e médio e desenvolvimento de materiais didáticos. Assim, desde 1991, desenvolvem-se ações que abarcam os três níveis de ensino - fundamental, médio e superior -, englobando de maneira integrada o ensino (graduação e pós-graduação), a pesquisa (dissertações de mestrado, teses de doutorado, artigos científicos, comunicações em congressos) e a extensão (artigos de divulgação científica, conferências, cursos, palestras, simpósios, mesas-redondas etc.).

As atividades voltadas para a Educação para a Ciência, especificamente na linha de pesquisa denominada Ensino de Química, iniciaram-se no então Departamento de Química do Instituto de Ciências Exatas, com a implantação do Laboratório de Pesquisas em Ensino de Química - LPEQ (SILVA et alii, 2011). Naquela ocasião, o LPEQ contava com dois docentes - Prof. Dr. Roberto Ribeiro da Silva e Prof. a MSc. Maria Beatriz Monteiro - responsáveis pela oferta das disciplinas de metodologia do ensino de Química para o curso Licenciatura em Química.

Com a implantação do curso noturno de Licenciatura em Química, a partir de 1993, o IQ/UnB promoveu a contratação de mais quatro docentes que atuam no Laboratório de Pesquisas em Ensino de Química. Dessa forma, foi então institucionalizada no IQ/UnB a Área denominada Ensino de Química, que conta atualmente com seis docentes, que constituem, administrativamente, a Divisão de Ensino de Química. Todos atuam no Curso de Licenciatura em Química e no Programa de Pós-Graduação em Ensino de Ciências.

O documento intitulado "Projeto Acadêmico Orgânico dos Cursos Noturnos de Licenciatura: Uma Nova Política de Formação de Professores" da Universidade de Brasília recomenda que cada curso aloque parcela significativa da sua carga horária em disciplinas de Didática Específica, as quais devem aprofundar a relação entre conteúdo específico e suas estratégias de ensino (SILVA; GAUCHE; SANTOS, 1997). Tais disciplinas devem ser ministradas, preferencialmente, pelas unidades acadêmicas responsáveis pelo curso e por profissionais que atuem na interface do conhecimento específico e de ensino, com atividades em ensino, pesquisa e extensão. Nesse sentido, 
os professores da Divisão de Ensino de Química do IQ/UnB assumiram a responsabilidade de diversas disciplinas de graduação do curso de Licenciatura.

No LPEQ, desenvolvem-se atividades das disciplinas de licenciatura, atividades de pesquisas em Ensino de Química e atividades de projetos de extensão. As atividades de pesquisa iniciaram-se concomitantemente com as atividades de extensão e ensino, tendo a primeira como fonte dos problemas de pesquisa. Em 2004, no entanto, com a criação do Programa de Pós-Graduação em Ensino de Ciências - PPGEC/UnB -, as respectivas atividades de pesquisa foram institucionalmente incorporadas ao LPEQ.

De um modo geral, os trabalhos de pesquisa desenvolvidos no âmbito do LPEQ enquadram-se basicamente dentro das seguintes linhas:

- Ensino de Química: Concepções e Processo Ensino-Aprendizagem;

- Formação de Professores;

- Materiais de Ensino de Química;

- Ensino de Química e Alunos com Necessidades Educacionais Especiais;

- Educação Ambiental.

Diversos projetos de pesquisas têm sido desenvolvidos, além dos que geraram dissertações e teses na Área. O Projeto Integração Universidade-Escola já obteve recursos de diversas agências financiadoras e gerou diversas publicações científicas. Nesse projeto, os professores do LPEQ prestam assessoria, a partir das demandas trazidas pelos professores e alunos da educação básica, em torno de questões conceituais, de atividades didáticas, de atividades experimentais, realização de feiras de ciências etc. No LPEQ, também, são desenvolvidas atividades do Projeto UnB Tour, as quais incluem palestras e apresentação de experimentos demonstrativos. Diversos alunos da graduação têm atuado nesses projetos, tendo sido contemplados com bolsas de iniciação científica e bolsas de extensão.

Desde a criação dos cursos noturnos de Licenciatura da Universidade de Brasília, em 1993, emergiu a perspectiva de fortalecimento das respectivas Áreas de Ensino, principalmente as de Biologia, de Física, de Matemática e de Química, por meio da consolidação de um programa interunidades de pós-graduação que atendesse às necessidades constatadas no contexto educacional dos ensinos médio e fundamental, e mesmo dos cursos de formação inicial. Nesse sentido, a Divisão de Ensino de Química, com a especialização dos seus docentes, propôs, ao final do ano de 2001, a criação da Área de Concentração "Ensino de Química”, a ser inserida no Programa de Pós- 
Graduação em Química, proposta essa aprovada pelo Colegiado do referido programa, mas que recebeu, da Câmara de Pesquisa e Pós-Graduação da UnB, a recomendação de criação de um Programa de Pós-Graduação em Ensino de Química que viesse a ser o núcleo inicial de um programa multidisciplinar, nos moldes dos que eram avaliados pela Capes na então Área de Ensino de Ciências e Matemática (Área 46), ao qual viriam a se agregar outras Áreas de Concentração.

Em decorrência de diferenças entre os percursos das Áreas em suas respectivas unidades acadêmicas, optou-se pela implementação do Programa de Pós-Graduação em Ensino de Ciências na UnB (PPGEC/UnB) ${ }^{1}$ por meio da criação do Curso de Mestrado Profissional em Ensino de Ciências, naquele momento, nas Áreas de Concentração Ensino de Química e Ensino de Física².

Em documento preliminar de subsídio às discussões em torno da criação do Mestrado Profissional em Ensino de Ciências ${ }^{3}$, informava-se que nas últimas décadas as Áreas de "Ensino de" (Física, Química e Biologia) e de Educação Matemática vinha crescendo e se definindo dentro de suas especificidades, isso tanto no Brasil quanto em muitos outros países. Em nosso país, em especial por meio de agências de fomento à pesquisa e à formação de recursos humanos - incluída a Capes -, surgiram comunidades de pesquisadores que produziram um considerável corpo de conhecimentos reconhecidos pelas comunidades internacionais correspondentes. No entanto, apesar do esforço dessas comunidades, tais conhecimentos não tiveram ainda o impacto desejado no sistema escolar. Diante dessa evidência, tornaram-se necessárias ações que revertessem o quadro. Três áreas foram identificadas, nas quais ações em nível de pósgraduação stricto sensu deveriam contribuir significativamente para as transformações necessárias:

1) A formação de professores dos ensinos fundamental e médio que possam, tanto no âmbito de seus locais de trabalho quanto no horizonte de suas regiões, atuar como iniciadores e líderes nos processos de formação de grupos de trabalho e estudo, compostos por professores; é evidente que esta formação dirigir-se-á também, e necessariamente, a melhorar a qualificação do professor (...) em sua prática pedagógica. A proposta de atuação nesta área diferencia-se das atuais especializações para professores e de programas como o PróCiências em dois aspectos: (i) não se volta apenas para a formação do

\footnotetext{
${ }^{1}$ http://www.unb.br/ppgec

${ }^{2}$ Aprovado pela Capes, no âmbito da Área 46, em dezembro de 2003.

${ }^{3}$ CAPES - Área de Ensino de Ciências e Matemática. MESTRADO (PROFISSIONAL) EM ENSINO
}

DE CIÊNCIAS E MATEMÁTICA. Brasília: mimeo, dezembro de 2000. 
professor como professor - certamente um papel importante - , mas também para a formação de professores multiplicadores; (ii) a formação stricto sensu, sendo parte do sistema de avaliação da CAPES, deve seguir o mesmo padrão de qualidade dos mestrados acadêmicos e doutorados.

2) A formação de profissionais que possam atuar de forma adequada em: desenvolvimento e implementação curricular, coordenação e orientação - inclusive de grupos de trabalho formados por professores -, e nos diversos processos de avaliação próprios do sistema escolar. A qualificação destes profissionais, de central importância no sistema escolar, tem se dado de três formas claramente inadequadas: (i) através da experiência de muitos anos de docência, na maioria dos casos sem oportunidade para reflexão e aprofundamento do que há de específico neste papel; (ii) em cursos de graduação nos quais está de todo ausente qualquer especificidade relativa às áreas de Ensino de Física, Química e Biologia e de Educação Matemática; (iii) em programas de pós-graduação acadêmica que, dirigindo-se à formação do pesquisador, não podem atender e, efetivamente, não atendem às especificidades dos papéis profissionais a serem exercidos. 3) A formação de docentes das disciplinas "de conteúdo" das licenciaturas nas áreas específicas. Talvez esteja aqui a mais premente demanda entre as áreas indicadas em 1, 2 e 3. Seguindo uma visão fortemente enraizada em nosso sistema de formação de professores, o que se tem, nas áreas a que se refere este documento, é uma tradição que concebe a formação do professor como uma combinação de "saber os conteúdos" ("puros") com um "saber ensinar" (também "puro"). Embora a pesquisa mais recente indique claramente a insuficiência desta visão, este é o quadro que se encontra em nossas licenciaturas, com muito poucas exceções. A formação que os mestrados aqui caracterizados pretenderão dar aos docentes das disciplinas "de conteúdo" das licenciaturas é tal que estes docentes sejam capazes de ministrar disciplinas "de conteúdo" que sejam disciplinas de serviço, isto é, particularmente voltadas para a formação profissional de professores das áreas já indicadas; é bastante sabido que a formação em mestrados das áreas específicas correspondentes não alcançam este objetivo de formação. (CAPES, 2000).

Com essa perspectiva, promovemos amplas discussões no processo de criação do Mestrado Profissional em Ensino de Ciências do PPGEC/UnB e assim o criamos, com o objetivo geral de promover, naquele primeiro momento, a qualificação de professores de Química e de Física em atividade docente no nível médio e em cursos superiores de Licenciatura em Química e em Física, em termos de conteúdos específicos e dos aspectos teóricos, metodológicos e epistemológicos do Ensino de Ciências. Os objetivos específicos estabelecidos foram: fomentar a produção e difusão de novos recursos instrucionais para o ensino médio de Química e de Física; ampliar o número de profissionais qualificados com alto nível de formação para o Ensino de Química e de Física; estabelecer intercâmbios institucionais com as escolas de ensino médio, visando à qualificação da prática docente e ao desenvolvimento de novos recursos de ensino; 
contribuir para o conhecimento da realidade educacional; consolidar estratégias de articulação pesquisa-ensino-extensão nas Áreas de Ensino de Química e de Física; fortalecer os Grupos de Pesquisa em Ensino de Química e de Física da Universidade de Brasília, consolidando a sua liderança como núcleo de difusão das pesquisas nessas Áreas na Região Centro-Oeste.

Em 2007, foi criada a Área de Concentração Ensino de Biologia, ampliando positivamente as perspectivas do Programa.

A qualificação de professores pressupõe conhecimentos específicos nas Áreas de Ensino, o desenvolvimento de competências na análise crítica e no desenvolvimento de projetos e materiais curriculares de ciências e na análise de sua prática pedagógica em sala de aula. Além disso, há necessidade de qualificação em termos de conteúdo, haja vista que os currículos de Química, de Física e de Biologia na Educação Básica continuam desatualizados, centrados em conceitos desenvolvidos em meados do século XIX. Essa falta de atualização conceitual tem-se configurado em um dos obstáculos ao aprendizado de conceitos químicos, físicos e biológicos, que muitas vezes são apresentados aos alunos pelos livros didáticos de forma imprecisa.

O Mestrado Profissional tem caráter terminal, objetivando, prioritariamente, a melhora da qualificação profissional docente. O mestrando, obviamente, poderá vir a se doutorar e se tornar um pesquisador na Área, mas o Mestrado Profissional em Ensino de Ciências não tem como objetivo principal prepará-lo para isso. Assim, a base, ou sustentação, da pesquisa desse mestrado é construída principalmente por meio de projetos desenvolvidos pelos docentes a partir da implementação de estratégias e materiais de ensino que deverão caracterizar o trabalho de conclusão do mestrado.

O Mestrado Profissional em Ensino de Ciências visa, portanto, a uma melhor qualificação profissional na área docente, abordando questões de ensino-aprendizagem, currículo e sistema escolar, na perspectiva da Educação em Ciências. Está dirigido de maneira explícita para a melhora da educação nessa área, quer pela ação direta em sala de aula, quer pela contribuição na busca de solução de problemas educativos em Ciências nos níveis da educação básica e do ensino superior (no que se refere à formação de professores das Licenciaturas).

A inserção dos mestrandos no contexto da prática docente é exigida, quando da seleção de candidatos, que ocorre anualmente. Nos editais, para inscrição nos processos seletivos, exige-se comprovação de vínculo empregatício como professor da área de 
Ciências da educação básica, ou como professor de ensino superior de Licenciatura na área de Ciências ou afim, ou comprovante de que tenha possuído tal vínculo nos últimos 12 meses, a considerar o período de inscrição. No caso de candidatos sem vínculo empregatício, deve-se comprovar ser licenciado e apresentar declaração de ter participado em projeto de pesquisa/extensão em ensino de Ciências e uma cópia do referido projeto; ou de que trabalha em instituição ou órgão relacionado à educação com pertinência à área de ensino de Ciências, tendo de apresentar arrazoado que justifique a importância do mestrado para sua atuação profissional.

A concepção de formar o professor de Química a partir da reflexão de sua prática (GAUCHE et alii, 2008; GAUCHE et alii, 2009) tem caracterizado as linhas de pesquisa de nosso Programa, que se encontra em processo de revisão curricular que resultará em apenas uma Área de Concentração, denominada Ensino de Ciências, com duas linhas de pesquisa:

Formação de Professores de Ciências da Natureza, que visa a investigar a formação e a prática docente de ensino de Ciências, no que se refere à natureza dos processos educacionais, considerando o saber docente em sua característica plural, analisando suas múltiplas interfaces e os diversos fatores que possibilitam o aprimoramento profissional, com vistas à proposição de ações que melhorem o ensino de Ciências; e

Ensino-Aprendizagem em Ciências da Natureza em seus múltiplos aspectos, que visa a compreender processos de ensino-aprendizagem em Ciências, em seus múltiplos aspectos e contextos, fazendo uso de diferentes materiais, metodologias e tecnologias, permitindo a avaliação e a produção de recursos didáticos, consideradas as necessidades dos alunos.

Até este ano de 2011, ainda com a existência da Área de Concentração Ensino de Química, as pesquisas têm-se pautado de acordo com as seguintes linhas de pesquisa abaixo especificadas.

\section{Linhas de Pesquisa - Área de Concentração Ensino de Química 1. ENSINO DE QUÍMICA: CONCEPÇÕES E PROCESSO ENSINO- APRENDIZAGEM}

OBJETIVOS: Investigar concepções de professores e alunos relativas ao processo ensino-aprendizagem e suas respectivas repercussões no ensino de Química.

2. ENSINO DE QUÍMICA E ALUNOS COM NECESSIDADES EDUCACIONAIS ESPECIAIS 
Ensino, Saúde e Ambiente -VV4 (2), pp. 58-70, ago. 2011

OBJETIVOS: Investigar dificuldades encontradas por alunos com Necessidades Educacionais Especiais, relacionadas a aprendizagem de conceitos da Química; propor e avaliar materiais e estratégias inclusivas.

\section{FORMAÇÃO DE PROFESSORES}

OBJETIVOS: Investigar a prática docente de ensino de Química e Ciências, visando à proposição de ações de formação inicial e continuada de professores.

\section{MATERIAIS DE ENSINO DE QUÍMICA}

OBJETIVOS: Desenvolver e avaliar materiais de ensino de Química.

A estrutura curricular do curso é constituída por disciplinas, elaboração de dissertação e prática docente supervisionada, em conformidade com o previsto pela Capes para os mestrados profissionais em Ensino. As disciplinas são organizadas em três categorias, a saber:

I. Tronco Comum - disciplinas de formação comum a todas as áreas de concentração do curso, que constituem o núcleo de estudos básicos e gerais, garantindo a formação didático-pedagógica e destacando visões contemporâneas de ensino, aprendizagem, currículo e avaliação, aspectos históricos, sociais e epistemológicos das ciências, e uso de novas tecnologias, além da prática docente supervisionada;

II. Área de Concentração - disciplinas da respectiva área de concentração, contemplando formação na área específica, com ementas próprias e bibliografia atualizada, direcionadas ao ensino, enfatizando a conceitualização, a fenomenologia e a transposição didática;

III. Domínio Conexo - disciplinas de qualquer programa de PósGraduação stricto sensu, oferecidas pela UnB, desde que aprovadas pelo orientador e pela Comissão de Pós-Graduação. (REGULAMENTO DO PROGRAMA, Artigo 21).

Enquanto o mestrado acadêmico - que demanda dedicação exclusiva, em particular por decorrência dos contratos de bolsas - cria um afastamento físico do local de trabalho, o Mestrado Profissional pressupõe exatamente o oposto. 'É importante que se entenda que o afastamento crítico se dá no plano teórico, na construção da capacidade da reflexão crítica, e é a isto que se refere a noção de professor reflexivo, inserido em sua prática profissional"4. Dessa forma, como o Mestrado Profissional

\footnotetext{
${ }^{4}$ CAPES - Área de Ensino de Ciências e Matemática. MESTRADO (PROFISSIONAL) EM ENSINO
} DE CIÊNCIAS E MATEMÁTICA. Brasília: mimeo, dezembro de 2000. 
impõe que a reflexão seja feita "a partir de" e "de forma concomitante com" a prática profissional do mestrando, não existe hiato ou readaptação após a conclusão do curso.

Conforme a concepção original de cursos dessa natureza, enquanto o caráter da dissertação no mestrado acadêmico é o de um relatório de pesquisa, a dissertação exigida no Mestrado Profissional configura-se como uma proposta de ação profissional que possa ter, de modo mais ou menos imediato, impacto no sistema a que ele se dirige. Nesse sentido, inclusive, há resolução específica no âmbito do PPGEC/UnB:

[...] Considerando que o Mestrado Profissional em Ensino de Ciências é voltado explicitamente para a evolução do sistema de ensino - seja pela ação direta em sala de aula, seja pela contribuição na solução de problemas dos sistemas educativos, nos níveis fundamental e médio, e no nível superior na formação de professores das Licenciaturas nas áreas envolvidas -, a Dissertação, em cumprimento ao Regulamento do PPGEC, teórica e metodologicamente fundamentada, deverá ter característica de:

1 - trabalho de pesquisa profissional aplicada - este entendido como o que contém:

a) explicitação do(s) problema(s) enfocado(s) na Dissertação, e b) proposição de ação profissional docente que contribua para a solução do(s) problema(s) explicitado(s), por meio de processos e/ou de materiais, consideradas as condições reais do contexto escolar; e

2 - ter potencial de impacto no respectivo sistema de ensino - entendido como o que, em forma e conteúdo, seja decorrente de proposição que possa ser utilizada por outros profissionais, especialmente os do sistema a que se dirige. (RESOLUÇÃO PPGEC N. ${ }^{\circ}$ 02/2004, grifos nossos).

Tal perspectiva coaduna-se com o que já discutimos em trabalho anterior (SANTOS et alii, 2003), em relação ao trabalho desenvolvido no âmbito de nosso Grupo de Pesquisa, qual seja o de adotar o princípio da "formação pela reflexão sobre a prática pedagógica, por meio de ações de pesquisa e extensão voltadas à mudança dessa mesma prática" (p. 1-2).

$\mathrm{O}$ que se pretende e se tem conseguido com este mestrado é que os alunos possam refletir ao longo do curso sobre a sua prática docente e que busquem, em conformidade com o contexto educacional no qual estão inseridos, novas práticas que resultem em mudanças no processo ensino-aprendizagem de Química. Nesse sentido, os projetos de pesquisas que estão em andamento visam à busca de desenvolvimento de novas propostas para o ensino de Química. 
Importante frisar que a proposição decorrente da pesquisa associada à dissertação elaborada não pode prescindir de avaliação que assegure sua viabilidade concreta no sistema de ensino ao qual se dirige. Preferencialmente, espera-se que tenha sido testada em contexto real, pelo próprio autor, mestrando do PPGEC/UnB. Dessa forma, evita-se proposição desprovida de consistência e sem ter sido devidamente submetida a critérios de validação, em especial por ter "potencial de impacto", o que pressupõe ser passível de utilização por pares, em seus respectivos contextos, com as devidas adaptações.

Até o presente momento, vinte e nove (29) dissertações foram defendidas, especificamente vinculadas ao Ensino de Química. O quadro a seguir sintetiza o resultado das pesquisas desenvolvidas, geradoras de artigos, trabalhos completos e resumos apresentados nos mais importantes eventos da Área de Pesquisa em Ensino de Química e de Ciências e capítulos de livros.

Quadro 1 - Síntese das dissertações defendidas, no âmbito do Mestrado Profissional do PPGEC/UnB, mais especificamente as vinculadas ao Ensino de Química, e respectivas proposições decorrentes.

\begin{tabular}{|c|c|c|}
\hline Ano & Título & Proposição \\
\hline \multirow{8}{*}{2006} & $\begin{array}{l}\text { 1. Critérios para avaliação de livros } \\
\text { didáticos de Química para o ensino } \\
\text { médio }\end{array}$ & $\begin{array}{l}\text { Planilha para avaliação de } \text { livros } \\
\text { didáticos de Química para } \\
\text { médio }\end{array}$ \\
\hline & $\begin{array}{l}\text { 2. A história da borracha na Amazônia e } \\
\text { a Química Orgânica: produção de um } \\
\text { vídeo didático/educativo para o ensino } \\
\text { médio }\end{array}$ & Vídeo didático para o ensino de Química \\
\hline & $\begin{array}{l}\text { 3. O ensino médio e a possibilidade de } \\
\text { articulação da escola com o trabalho }\end{array}$ & $\begin{array}{l}\text { Unidade de ensino: a construção de um } \\
\text { protótipo didático de um aquecedor solar }\end{array}$ \\
\hline & $\begin{array}{l}\text { 4. Formação contínua do professor de } \\
\text { Ciências: pesquisa colaborativa na } \\
\text { construção de uma proposta de } \\
\text { coordenação reflexiva }\end{array}$ & $\begin{array}{l}\text { Texto de apoio: Coordenação } \\
\text { pedagógica reflexiva na perspectiva da } \\
\text { formação contínua do professor }\end{array}$ \\
\hline & $\begin{array}{l}\text { 5. A inter-relação dos conhecimentos } \\
\text { cientifico, cotidiano e escolar no ensino } \\
\text { de gases }\end{array}$ & $\begin{array}{l}\text { Módulo de Ensino: a inter-relação dos } \\
\text { conhecimentos científicos, cotidiano e } \\
\text { escolar no ensino de gases }\end{array}$ \\
\hline & $\begin{array}{l}\text { 6. O professor diante do espelho: } \\
\text { constituição de um instrumento para } \\
\text { pesquisa e formação continuada de } \\
\text { professores de Ciências }\end{array}$ & $\begin{array}{l}\text { Texto de apoio: constituição de grupos } \\
\text { colaborativos na escola: proposta para } \\
\text { um processo de formação continuada de } \\
\text { professores }\end{array}$ \\
\hline & $\begin{array}{l}\text { 7. Educação ambiental no ensino de } \\
\text { Química: criando trilhas em uma escola } \\
\text { pública do DF }\end{array}$ & $\begin{array}{l}\text { Guia de educação ambiental para } \\
\text { abordagem temática em aulas de } \\
\text { Química }\end{array}$ \\
\hline & $\begin{array}{l}\text { 8. Aprendendo a imaginar moléculas: } \\
\text { uma proposta de ensino de geometria } \\
\text { molecular }\end{array}$ & $\begin{array}{l}\text { Proposta de ensino de geometria } \\
\text { molecular do componente curricular } \\
\text { Química do ensino médio associada à } \\
\text { utilização de imagens. }\end{array}$ \\
\hline
\end{tabular}




\begin{tabular}{|c|c|c|}
\hline \multirow{6}{*}{2007} & $\begin{array}{l}\text { 9. Aprendizagem cooperativa no ensino } \\
\text { de Química: uma proposta de } \\
\text { abordagem em sala de aula }\end{array}$ & $\begin{array}{l}\text { Texto de apoio ao professor de Química: } \\
\text { aprendizagem cooperativa na prática: } \\
\text { uma proposta para o ensino de Química }\end{array}$ \\
\hline & $\begin{array}{l}\text { 10. Pesquisa colaborativa e comunidades } \\
\text { de aprendizagem: possíveis caminhos } \\
\text { para a formação continuada }\end{array}$ & $\begin{array}{l}\text { O desenvolvimento de comunidades de } \\
\text { aprendizagem como estratégia para a } \\
\text { formação continuada de professores }\end{array}$ \\
\hline & $\begin{array}{l}\text { 11. A informática como instrumento } \\
\text { mediador do ensino de Química aplicada } \\
\text { na formação inicial dos professores }\end{array}$ & $\begin{array}{l}\text { Material de apoio para professores: } \\
\text { informática para o ensino de Química }\end{array}$ \\
\hline & $\begin{array}{l}\text { 12. Educação de jovens e adultos: } \\
\text { proposta de material didático para o } \\
\text { ensino de Química }\end{array}$ & $\begin{array}{l}\text { Educação de jovens e adultos: proposta } \\
\text { de material didático para o ensino de } \\
\text { Química }\end{array}$ \\
\hline & $\begin{array}{l}\text { 13. Educação Ambiental em Aulas de } \\
\text { Química em uma Escola Pública: } \\
\text { Sugestões de Atividades para o } \\
\text { Professor a partir da Análise da } \\
\text { Experiência Vivenciada durante um ano } \\
\text { letivo }\end{array}$ & $\begin{array}{l}\text { Texto de apoio: educação ambiental em } \\
\text { aulas de Química - orientações ao } \\
\text { professor }\end{array}$ \\
\hline & $\begin{array}{l}\text { 14. A inter-relação entre saberes } \\
\text { científicos e saberes populares na escola: } \\
\text { uma proposta interdisciplinar baseada } \\
\text { em saberes das artesãs do Triângulo } \\
\text { Mineiro }\end{array}$ & $\begin{array}{l}\text { Texto de apoio: } \\
\text { Tecendo Saberes }\end{array}$ \\
\hline \multirow{5}{*}{2008} & $\begin{array}{l}\text { 15. A Inserção da Escola na } \\
\text { Comunidade: Desenvolvendo Projetos } \\
\text { na Perspectiva de uma Educação pelo } \\
\text { Trabalho }\end{array}$ & $\begin{array}{l}\text { A inserção da escola na comunidade: } \\
\text { desenvolvendo projetos na perspectiva } \\
\text { de uma educação pelo trabalho }\end{array}$ \\
\hline & $\begin{array}{l}\text { 16. A História da Ciência e a } \\
\text { Experimentação no Ensino de Química } \\
\text { Orgânica }\end{array}$ & $\begin{array}{l}\text { Módulo de ensino: a História da Ciência } \\
\text { e a experimentação no ensino de } \\
\text { Química Orgânica }\end{array}$ \\
\hline & $\begin{array}{l}\text { 17. Abordagem de Questões } \\
\text { Socioambientais por meio de tema CTS: } \\
\text { Análise de Prática Pedagógica no Ensino } \\
\text { Médio de Química e Proposição de } \\
\text { Atividades }\end{array}$ & $\begin{array}{l}\text { Sugestão de atividades socioambientais } \\
\text { por meio de tema CTS em aulas de } \\
\text { Química }\end{array}$ \\
\hline & $\begin{array}{l}\text { 18. Questões socioambientais no Ensino } \\
\text { de Ciências: Superando Visões } \\
\text { Naturalistas no Ensino Fundamental }\end{array}$ & $\begin{array}{l}\text { Temas socioambientais para a sala de } \\
\text { aula }\end{array}$ \\
\hline & $\begin{array}{l}\text { 19. O Reuso da Água como Tema } \\
\text { Gerador para o Desenvolvimento do } \\
\text { Processo de Ensino Aprendizagem de } \\
\text { Química }\end{array}$ & Água: uma proposta de uso e reuso \\
\hline \multirow{4}{*}{2009} & $\begin{array}{l}\text { 20. A História da Ciência e a } \\
\text { Experimentação na Constituição do } \\
\text { Conhecimento Escolar: A Química e as } \\
\text { Especiarias }\end{array}$ & 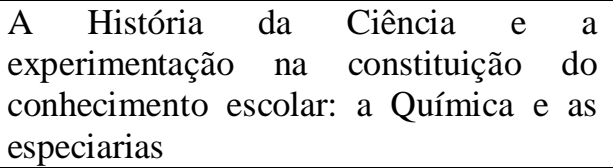 \\
\hline & $\begin{array}{l}\text { 21. Construção de uma Matriz de } \\
\text { Planejamento e Avaliação em Ensino de } \\
\text { Química }\end{array}$ & $\begin{array}{l}\text { Construção de uma matriz de } \\
\text { planejamento e avaliação em ensino de } \\
\text { Química: texto de apoio ao professor }\end{array}$ \\
\hline & $\begin{array}{l}\text { 22. Fontes de Energia - Usos e } \\
\text { Consequências. Proposta de Material } \\
\text { Didático para o Ensino de Química }\end{array}$ & $\begin{array}{l}\text { Material didático para o ensino de } \\
\text { Química: fontes de energia - usos e } \\
\text { consequências. }\end{array}$ \\
\hline & $\begin{array}{l}\text { 23. A produção de papel artesanal de } \\
\text { fibra de bananeira: }\end{array}$ & Material paradidático \\
\hline
\end{tabular}




\begin{tabular}{|c|c|c|}
\hline & $\begin{array}{l}\text { Uma proposta de ensino de Química por } \\
\text { projeto }\end{array}$ & \\
\hline \multirow{4}{*}{2010} & $\begin{array}{l}\text { 24. Construindo Estruturas Químicas de } \\
\text { Substâncias Desconhecidas: } \\
\text { Proposta de Material Paradidático }\end{array}$ & $\begin{array}{l}\text { Fórmulas e estruturas químicas: de onde } \\
\text { vêm? Elucidação estrutural por análises } \\
\text { físicas e químicas }\end{array}$ \\
\hline & $\begin{array}{l}\text { 25. Experimentação no Ensino de } \\
\text { Ciências: Atividades Problematizadas e } \\
\text { Interações Dialógicas }\end{array}$ & $\begin{array}{l}\text { Experimentação no Ensino de Ciências } \\
\text { no nível fundamental II: atividades } \\
\text { problematizadas e interaçóes dialógicas } \\
\text { para os conteúdos de ar e água }\end{array}$ \\
\hline & $\begin{array}{l}\text { 26. Proposta de Guia para Apoiar a } \\
\text { Prática Pedagógica de Professores de } \\
\text { Química em Sala de Aula Inclusiva com } \\
\text { Alunos que Apresentam Deficiência } \\
\text { Visual }\end{array}$ & $\begin{array}{l}\text { Guia com Subsídios Básicos Para a } \\
\text { Prática Pedagógica em Ciências com } \\
\text { Alunos Deficientes Visuais no Ensino } \\
\text { Médio }\end{array}$ \\
\hline & $\begin{array}{ll}\text { 27. Estratégias de Ensino-Aprendizagem } \\
\text { de Conceitos } & \text { Relacionados ao Tema } \\
\text { Equilíbrio } & \text { Químico } \\
\text { Modelagem e Modelos }\end{array}$ & $\begin{array}{l}\text { Texto de Apoio a Professores de } \\
\text { Química: estratégias de ensino- } \\
\text { aprendizagem de conceitos relacionados } \\
\text { ao tema equilíbrio químico utilizando } \\
\text { modelagem e modelos }\end{array}$ \\
\hline \multirow[t]{2}{*}{2011} & $\begin{array}{l}\text { 28. Nutrição para a Promoção da Saúde: } \\
\text { Um Tema Químico Social Auxiliando } \\
\text { na Compreensão do Conceito de } \\
\text { Transformação Química }\end{array}$ & $\begin{array}{l}\text { Módulo de ensino: Desvendando a } \\
\text { composição química dos alimentos e sua } \\
\text { importância para a saúde }\end{array}$ \\
\hline & $\begin{array}{l}\text { 29. Ligação metálica: uma proposta de } \\
\text { material didático de apoio ao professor } \\
\text { de Química em sala de aula }\end{array}$ & $\begin{array}{l}\text { Módulo de ensino: Atividades } \\
\text { experimentais para aulas de Ligações } \\
\text { Covalentes, Iônicas e Metálicas }\end{array}$ \\
\hline
\end{tabular}

\section{Considerações Finais}

Estamos em um contínuo processo de construção de um curso de Mestrado Profissional, na perspectiva de qualificação profissional de professores, por meio de pesquisa pela reflexão sobre a prática. Nele, temos procurado por em prática princípios da pesquisa a partir do e no contexto escolar, em um processo retroalimentador ensinopesquisa-extensão, que caracteriza as ações de nosso Grupo de Pesquisa (GAUCHE et alii, 2007; SANTOS et alii, 2006; SILVA et alii, 2011). Esse é o foco central do processo de formação de professor, o qual acreditamos que deve também se inserir na pós-graduação, especialmente em cursos de Mestrado Profissional.

Nesse sentido, ao apresentar uma síntese da história, da natureza, dos impactos, no contexto escolar, e das linhas de pesquisa do Programa de Pós-Graduação em Ensino de Ciências da Universidade de Brasília (PPGEC/UnB), em especial do Mestrado Profissional em Ensino de Ciências - Pesquisas em Ensino de Química, esperamos ter contribuído na perspectiva de ampliar a explicitação, socialização e análise de suas características, dos pressupostos teóricos que o fundamentam, bem como de resultados 
na prática do ensino escolar. É certo que somente uma discussão mais extensa, com aprofundamento teórico-metodológico dos diversos projetos em desenvolvimento, poderia dar a exata dimensão do papel da experiência da UnB no contexto escolar, no que tange às suas contribuições para o avanço do ensino e da formação em Química, no âmbito do país como um todo. Espera-se que as discussões que daqui decorram superem essa limitação.

\section{Referências Bibliográficas}

GAUCHE, R.; MÓL, G. S.; SILVA, R. R.; BAPTISTA, J. A.; MACHADO, P. F. L. Melhorando a própria atividade docente por meio da pesquisa. In: ZANON, L. B.; MALDANER, O. A. (Org.). Fundamentos e propostas de ensino de química para a educação básica no Brasil. Ijuí: Ed. Unijuí, 2007, v. , p. 211-217.

GAUCHE, R.; SILVA, R. R.; BAPTISTA, J. A.; SANTOS, W. L. P.; MÓL, G. S.; MACHADO, P. F. L. Formación de profesores de química: concepciones y propuestas. Educación Química, v. 18, p. 30-33, 2007.

Formação de Professores de química: concepções e proposições. Química Nova na Escola, n. 27, p- 26-29, 2008.

Formação de Professores de química na Universidade de Brasília: Construção de uma proposta de inovação curricular. Química Nova na Escola, vol. 31, n. 2, p140-150, 2009.

SANTOS, W. L. P.; GAUCHE, R.; MÓL, G. S.; SILVA, R. R.; BAPTISTA, J. A. Formação de professores: uma proposta de pesquisa a partir da reflexão sobre a prática docente. Ensaio - Pesquisa em Educação em Ciências. 2006, Volume 08, Número 1, p. 1-14.

Letramento científico e tecnológico e pesquisa sobre formação de professores: desafios e questões teórico-metodológicas. Apresentação oral no Workshop "A pesquisa em educação no Brasil: abordagens teórica e metodológica", 26 $6^{\mathrm{a}}$ Reunião Anual da Sociedade Brasileira de Química, Poços de Caldas - MG, Maio, 2003, 37 p. Disponível em: <http://sbqensino.foco.fae.ufmg.br>. Acesso em 26 mai. 2003.

SILVA, R. R; GAUCHE, R.; SANTOS, W. L. P.; Currículo de licenciatura em química da Universidade de Brasília: uma proposta em implantação. Química Nova, n. ${ }^{\circ}$ 20, p. 675-683, 1997.

SILVA, R. R.; GAUCHE, R.; BAPTISTA, J. A.; SANTOS, W. L. P.; MOL, G. S.; MACHADO, P. F. L. Laboratório de Pesquisas em Ensino de Química da Universidade de Brasília LPEQ/UnB: concepções, relatos e reflexões. Revista Virtual de Química, v. 3, p. 14-26, 2011. 